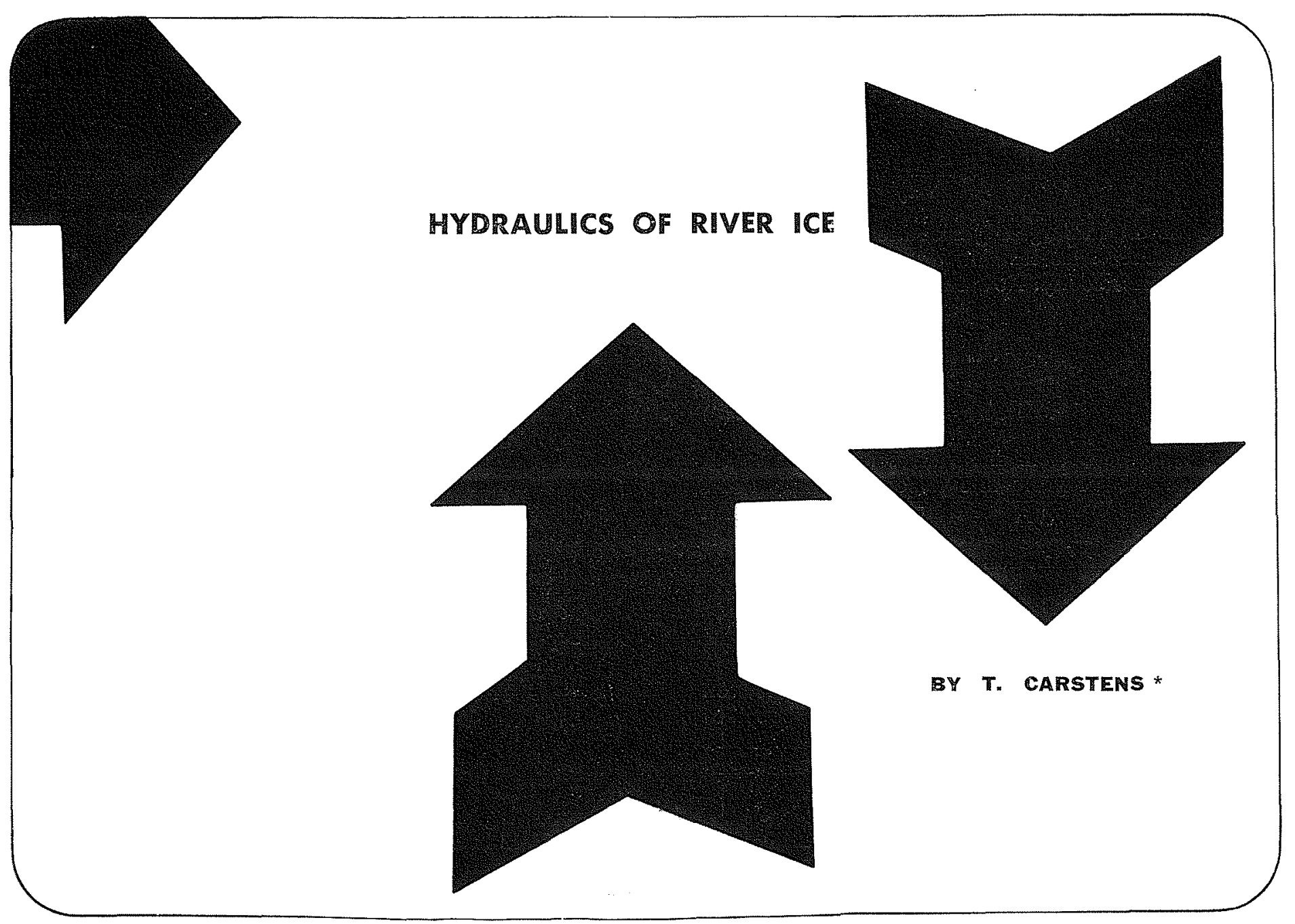

\section{Introduction}

Two-phase flow with a solid phase which is transported by the fluid phase, occurs in most natural streams. At least during some parts of the year this transport of solids is sufficiently great to concern the hydraulic engineer. The solid phase may be a) sediments, b) organic debris, c) logs and $d$ ) ice.

The transport of sediments in rivers has always been a major topic within civil hydraulies.

- The transport of organic debris thrown by the vegetative cover requires special protective measures for intakes in rivers almost everywhere.

-. The log floating is normally a controlled operation in which the stream's capacity for surface transport is exploited, subject to rules and regulations.

- The formation and transport of ice is a major hazard in Northern rivers and governs not only the use of the river of the river banks as well, often far beyond flood levels.

This paper describes the transport of a solid phase which is lighter than water, using terms from the more familiar transport of sediments. Our findings apply to most organic debris and to logs, but ice has been our main concern. A model

\footnotetext{
* Siver and Harbonr Laboratory at the Technical Univer-
} sity of Norway (Klatebueien 153, Trondheim). investigation of the Burfell intake on the river Thjorsá in Iceland, carried out at the River and Harbour Laboratory at the Technical University of Norway, illustrates most of the problems that are discussed.

Theory of suspensions

\section{Setiling particles.}

One of the firmly established results in sediment transportation theories is the distribution equation for small concentrations of suspended sediments in a two-dimensional stream, given by Vanoni (1946). We now propose to use this theory also for solid particles which are lighter than water and therefore have a negative fall velocity $w$.

The distribution formula is derived from the differential equation:

$$
c w=-\mathbf{E}_{c} \frac{d c}{d y} .
$$

Here $c w$ is the gravitational downward transport through unit horizontal area at the level $y$ above the stream bed with concentration $c$ of solid particles with fall velocity $w$. This transport is balanced by the (Fickian) diffusion of particles upward, in the direction of negative concentration gradient, $-d c / d y$. 


\section{T. CARSTENS}

The diffusion coefficient $\mathrm{E}_{c}$ for mass transfer is assumed equal to the eddy viscosity $\varepsilon_{m}$ for momentum transfer:

$$
\mathrm{E}_{c}=\varepsilon_{m}=l^{2} \frac{d u}{d y}
$$

where $l$ is the mixing length of the phenomenological turbulence theories and $d u / d y$ is the gradient of the mean velocity. Now the shear stress is given by:

and:

$$
\tau=\rho \varepsilon_{m} \frac{d u}{d y}
$$

$$
\tau=\tau_{0}\left(1-y / y_{0}\right)
$$

where $\tau_{0}$ is the boltom shear stress.

We assume a logarithmic velocity profile. (This assumption is well supported by measurements, but its derivation implies that $\tau=\tau_{0}$, whereas $\tau$ is actually a linear function of $\mathrm{y}$ given by (4)

$$
u=u_{*}\left(\frac{1}{x} \ln y+\mathrm{C}\right)
$$

where $u_{*}=\sqrt{\tau_{0} / p}$ is the shear velocity, $x$ is von Karman's "universal" constant and C a constant depending on the roughness and the Reynolds number of the flow. Differentiating (5) and combining with (2), (3) and (4) we get:

and:

$$
l=x y\left(1-y / y_{0}\right)_{2}^{1}
$$

$$
\mathrm{E}_{c}=x y u_{*}\left(1-y / y_{0}\right)
$$

Inserting (7) in (1) and integrating one obtains the distribution formula:

$$
\frac{c}{c_{a}}=\left(\frac{a\left(y_{0}-y\right)}{y\left(y_{0}-a\right)}\right)^{x / u_{*}}
$$

where $a$ is a reference level with (known) concentration $c_{a}$.

The difrusion coefficient $\mathrm{E}_{c}$ of (7) is plotted in Figure 1 and the familiar relative distribution $c / c_{a}$ of $(8)$ is plotted in Figure 2.

\section{Buoyant particles.}

For buoyant particles the fall velocity $w_{b}$ is negative. Introducing the new variables:

$$
\begin{gathered}
w_{b}=-w \\
y_{b}=y_{0}-y
\end{gathered}
$$

in (1) we obtain:

$$
c w_{b}=-\mathbf{E}_{c} \frac{d c}{d y_{b}}
$$

which is identical with (1) and has the same solution:

$$
\frac{c}{c_{a}}=\left(\frac{a\left(y_{0}-y_{b}\right)}{y_{b}\left(y_{0}-a\right)}\right)^{w_{2} / \kappa u_{*}}
$$

The set of curves on Figure 2 therefore applies equally well to particles with densities greater or less than water, provided $y$ is measured positive upwards from the bed when $w>0$ and positive downwards from the water surface when $w<0$.

This extension of the distribution formula to buoyant particles is also valid for two-phase flow in pipes, where $\mathrm{E}_{c}$ is symmetric with respect to the pipe axis. The fact that the velocity profiles in an open channel and in a closed pipe are different, may influence the concentration distribution through the dependence of $\mathrm{E}_{c}$ on $d u / d y$. However, as long as $\mathbf{E}_{c}$ is invariant under the transformation $y_{b}=y_{0}-y$, the distribution for buoyant particles can be derived from the distribution of settling particles through the substitutions $(9)$.

\section{Surface load}

Bed load is defined as that part of the total load which is largely supported by the bed. The bed load moves by rolling, sliding and jumping.

The term surface load is here introduced to describe that part of the total load which is transported at or near the free surface. The surface load capacity of a stream is much greater than its bed load capacity, because the surface itself has a velocity, while the bed is at rest. (Also, a surface load particle is accelerated more than the fluid and therefore moves at a somewhat higher speed than the surrounding fluid. A bed load particle, on the other hand, is moving slower than the surrounding fluid, partly because it is accelerated less than the fluid, but primarily because of bed friction. The acceleration effects are of little importance except on very steep slopes, however. An example is $\log$ chutes.)

\section{Removal of suriace load.}

Surface load cannot be separated from the fluid by a recess type of trap. The two remaining possibilities are $a$ ) mechanical removal and $b$ ) diversion of those fluid layers that contain the surface load.

Mechanical removal is used extensively at river intakes to clean their trash racks. Automatic raking devices have eliminated the clogging of intakes by buoyant or nearly weightless solids in the flow at temperalures above freezing.

However, such devices no longer function automatically during cold spells due to the formation of ice. A combination of hand raking and diversion of the surface layers then becomes necessary and is in fact the only recourse for a number of intakes in rivers with an ice regime.

The removal of surface load by diversion of the surface layers of fluid is a delicate hydraulic problem, which normally calls for reduced-scale model studies.

\section{Large floating solids.}

Two basic rules govern the transport of large floating solids, such as logs and ice floes:

1. The product of surface velocity and width cannot decrease beyond a minimum value in the direction of flow;

2. The transport capacity is increased by increasing surface velocities.

The first rule is derived from the continuity equation for the surface: 


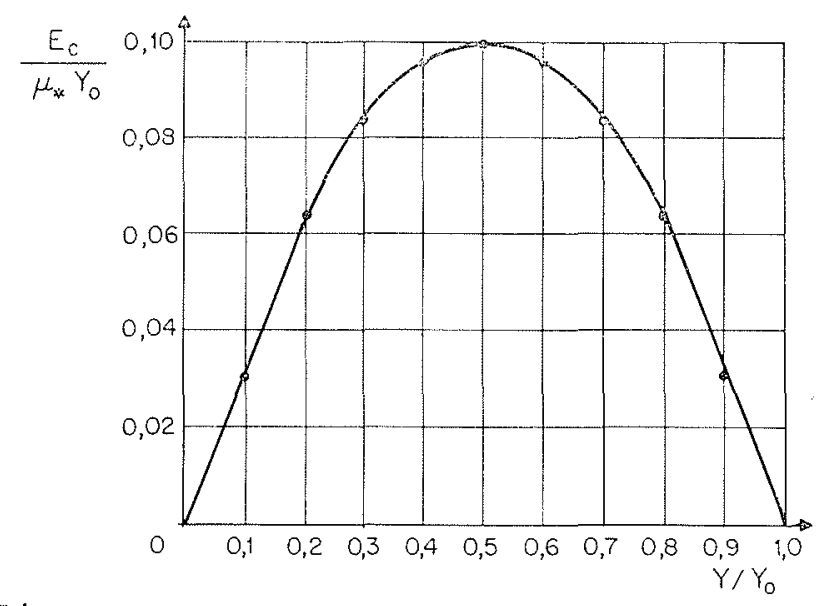

$1 /$

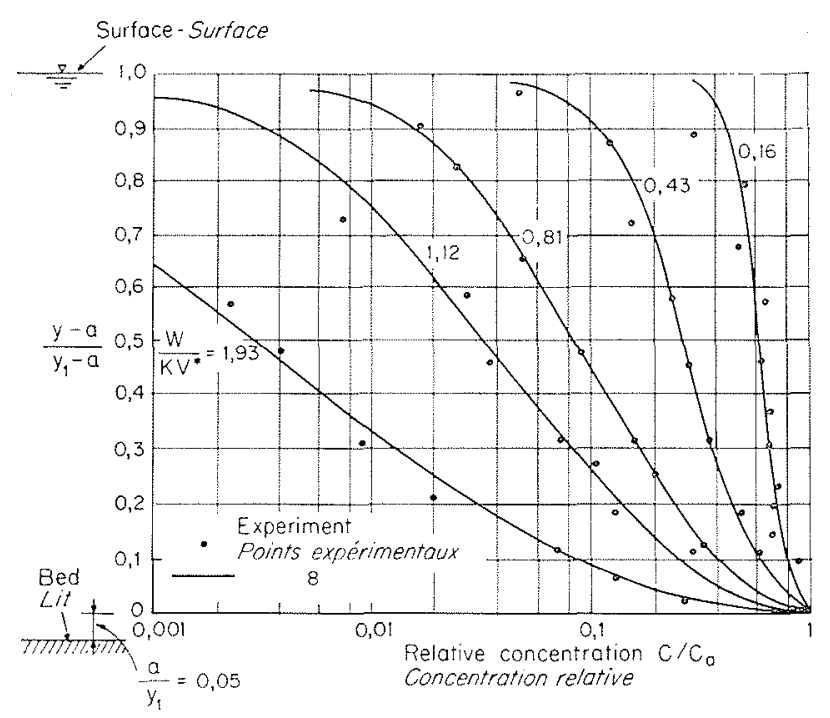

2)

$$
n_{a} \int_{0}^{b} v_{0} d l=\mathrm{constant}
$$

where $v_{0}$ is the surface velocity, $b$ the surface width and $n_{a}$ a coefficient indicating how much of the surface is covered by floating solids. Thus, as long as $n_{a}<n_{a \text { max }}$, a reduction of the integral in (11) may be compensated by an increase in $n_{a}$. The value of $n_{a \max }$ depends on the shape and size of the floating solids. (For logs $n_{a \text { max }}$ may range from 0,5 to 0,8 , for ice floes $n_{a \max }$ may approach 1.$)$

The second rule is also derived from (11), and states that the transport capacity is proportional to the integral.

The draft of the floating solids gives a minimum depth of flow through the diversion. In order to pass a certain discharge of solids with a minimum of water, one must find the minimum width. The diversion thus becomes an acceleration problem for the surface. Excellent log chutes have been designed using the simple rule:

$$
a=u \frac{d u}{d l}=\mathrm{constant}
$$

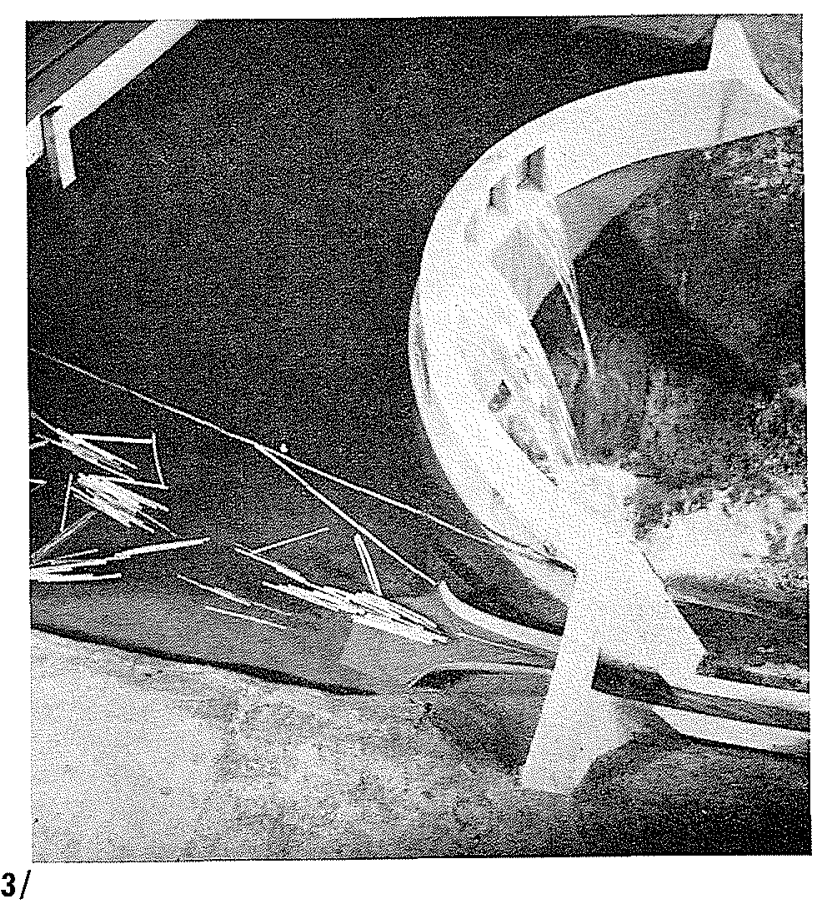

$1 /$ The diffusion coefficient $E_{c}$ as a function of water depth $y$. Variation du coefficient de diffusion $E_{\mathrm{c}}$ en fonction de la hauteur d'eall $\mathrm{y}$.

2/ The concentration distribution for suspended particles (after Vanoni).

Répartition des concentrations de matériaux en suspension (d'après Vanoni).

3/ Log chute entrance with constant convective acceleration. Entrée de la passe à bois, en régime d'accélération convective constante.

Figure 3 shows an example of a $\log$ chute entrance in which the convective acceleration (12) is constant.

\section{Small buoyant solids.}

For small solids, such as frazils, slush or leaves, which are easily thrown into suspension, the above procedure is no longer safe. It is not sufficient that the surface continuity is preserved in the broad sense of (11). In addition one must prescribe practical limits to the turbulent exchange between the surface and lower layers.

The fact is that one cannot increase the mean surface velocity at all without penalties in the form of increased concentrations of suspended solids. A working compromise therefore has to be found so that one does not attempt to separate solids after their concentration has been brought down to harmless levels. The design would normally have to be worked out on a reduced-scale model, and one would then look for a solution that diverts a chosen "design" size of solids, while admitting smaller sizes to pass through the intake. 
formula to compule the rate of ice transported as inverted bed load.

\section{River ice categories and problems}

In a river ice may form not only at the free surface as in a reservoir, but equally well at any fixed boundary exposed to the flow. More important still, it may form anywhere within the water mass as freely floating crystals, frazils.

Each reach of open river has its characteristic ice. The ice discharge passing any cross-section is a mixture of ice from all open reaches upstream. Depending on the physiography of the river, all, some, or only one of the following categories of ice may be present at the same time:

1. Solid sheet ice floes of high density, originating from an ice cover;

2. Less solid and less dense ice floes representing advanced stages of metamorphosis either of melting sheet ice or of freezing frazils;

3. Clusters and floes of loose ice, slush, representing early stages of metamorphosis of frazils, or trapped snow;

4. Frazils, freely floating crystals of freshly formed ice.

The two major hazards to a river intake are:

a) Accumulations of ice in front of the intake; and,

b) Withdrawal of too large concentrations of ice through the intake.

The larger and denser the ice floes are, the more easily they may form bridges across the river or its gated section and cause ice jams. On the other hand, the smaller and looser the ice clusters are, the more easily they are drawn through the intake.

In discussions of the latter hazard Devik has introduced the catch phrases "active ice" and "passive ice" to distinguish ice surrounded by supercooled water from ice surrounded by water at its freezing point. The former ice has a much greater tendency to stick to submerged objects than the latter. Any hydraulic structure can function without difficulties until the concentration of ice in the flow exceeds a certain limit. If the ice is active, however, this limit is only a fraction of the permissible concentration of passive ice.

\section{Suspended ice.}

Frazils come very close to the "ideal" suspended particles of the simple theory outlined above. In fact, because of their low fall velocity, the frazils probably fit Eq. (1) better than the river sediments for which this equation was derived.

However, the frazils do not remain for long in their elementary form. As their concentration increases, so does the number of collisions between them. Such collisions result in bonds between the frazils and the formation of flocks with a very open structure. The flocks, while drifting with the mean velocity just as the frazils, are not so easily thrown around by turbulent eddies. Because the flocks are larger than the frazils, it takes larger eddies to move them, and therefore they move less often than the frazils. Thus the diffusion coeffi- cient $\mathrm{E}_{c}$ is smaller for flocks than for frazils, and the concentration of ice at a certain depth therefore decreases as a consequence of flocculation.

This process has repeatedly been observed in a recirculating flume in a cold room at The Technical University of Norway and is reported by Tesaker (1965) and Carstens (1966). Michel (1963) observed the same sequence of events earlier in an outdoor flume at the Laval University, Quebec.

\section{Surface load of slush.}

As the flocculation proceeds, the surface becomes filled to capacity with slush- $n_{a \text { max }}$ in (11)-and is slowed down because of bank friction. The surface layer is now overtaken by the flow in the lower layers, and continued supply and "settling" of ice will increase $y_{s} / y_{0}$. At the same time more and more ice will emerge and ride the stream, as it were.

Enormous quantities of ice are transported in such slush layers in many rivers. The most notorious ice producers are probably found in Canada and in Iceland for two reasons. First, large heat reservoirs, in Canada lakes, in Iceland ground water, retard or prohibit the formation of ice covers. Second, if an ice cover forms, it does not become permanent because the weather fronts swing and cause frequent shifts from freezing to thawing.

Figures 4 and 5 show pictures from the river Thjorsá in Iceland during a heavy ice run. Figure 4 is taken upstream of a sill of anchor ice, where the depth is large and velocities low, so most of the slush has surfaced. Figure 5 is taken just downstream of the anchor ice sill; the drop in water level across the sill can be seen. Because of the decreased depth and also a decreased width, the flow velocities have increased, compared to what they are on fig. 4 Most of the slush now has disappeared from the surface and become suspended by the increased turbulence.

\section{River ice as a hydraulic problem.}

We have suggested, as have Hausser and Galiana (1959) before us, that the theory of suspensions applies to frazils. The increasing use of hydraulic models to solve many ice problems, notably in Canada, indicates that their hydraulic aspects are predominating.

This is not to say that heat flow problems are negligible. In fact, it is the potential for heat transfer that makes an active, supercooled flow behave so differently from a passive, zero degree flow.

\section{Model study of the Burfell diversion}

During the planning stages of the Burfell power plant on the river 'Thjorsá in Iceland, the River and Harbour Laboratory at the Technical University of Norway was asked to do a model study of the ice and sediment problems arising at the diversion dam.

The ice problem was described to us as being chiefly that of skimming off a passive slush from the upper layers of water and to pass the slush over 
the dam while expending a minimum amount of water.

A corresponding solution was conceived for the sediment problem. The sediments were to be trapped in a trench and flushed through a bottom outlet in the dam.

Design.-Figure 7 shows the project layout. In the original design, the power water is diverted through 12 ports, each $10 \mathrm{~m}$ long and $2 \mathrm{~m}$ high, in the right bank to an artificial pond. The ports are submerged $10 \mathrm{~m}$. The slush is supposed to surface in front of the ice wall above the ports and then to be drawn over the weir, either to the Bjarnalækur Canal or to the river. The sediment trench is merely an excavation in front of the diversion structure.

\section{Prototype characieristics.}

Water discharge.-At the damsite the Thjorsa drains an area of $6350 \mathrm{~km}^{2}$. Rainfall is distributed throughout the year, and this fact together with extensive infiltration largely masks the snowmelt flood. Figure 6 shows a map of the river system.

The water discharge has been derived from 15 years of stage records at the waterfall Urridafoss, $46 \mathrm{~km}$ downstream of the dam site. The average discharge is $338 \mathrm{~m}^{3} / \mathrm{s}$ and the observed range is from 72 to $1980 \mathrm{~m}^{3} / \mathrm{s}$. Probable maximum discharge computed from extreme hydrometeorological conditions is $7750 \mathrm{~m}^{3} / \mathrm{s}$.

Slush.-Measurements of slush discharge in the Thjorsá have been made by several methods. Sigurdsson (1964) sampled the river and estimated directly the slush discharge. Devik and Kanavin (1966) first revised Devik's heat loss formula to fit observed cooling rates and later obtained good agreement between prediced ice production and observed ice accumulations.

Observed slush discharges have been reported as high as $35 \mathrm{~m}^{3} / \mathrm{s}$. The probable maximum slush discharge is not governed by meteorological extremes such as the probable maximum flood. The rate of slush production may be written:

$$
Q_{s}=\frac{1}{L_{\Upsilon_{i} p}} q_{h} \mathrm{~A}_{h}
$$

where $L$ is the latent heat of fusion, $\gamma_{i}$ the specific weight of ice, $p$ the slush porosity, $q_{h}$ the rate of heat loss from unit area of free water surface and $A_{h}$ this free surface area. The area $A_{l}$ decreases as the concentration of ice increases and finally obtains a minimum value. The rate of heat loss from this minimum surface decreases as $Q_{s}$ increases further, because the slush emerges and shelters the patches of open water.

Thus the slush discharge rather rapidly approaches an upper bound. A high slush discharge, which for all practical purposes may be called the probable maximum, therefore does not call for extreme weather conditions and is not such a remote event as the probable maximum flood. In fact, the observed maximum slush discharge, $35 \mathrm{~m}^{3} / \mathrm{s}$, may not be far from the probable maximum value, but this question is still debated.

For the model tests a slush discharge of $55 \mathrm{~m}^{3} / \mathrm{s}$ was chosen as a maximum. This figure is higher than most estimates.

Ice floes. - During the winter 1966, which had unusually many degree-days of frost, more than $50 \%$ of the river surface became covered by bank ice and ice islands growing from the river bed. Some of this solid ice loosened and drifted past the dam site, demonstrating the need for mon-

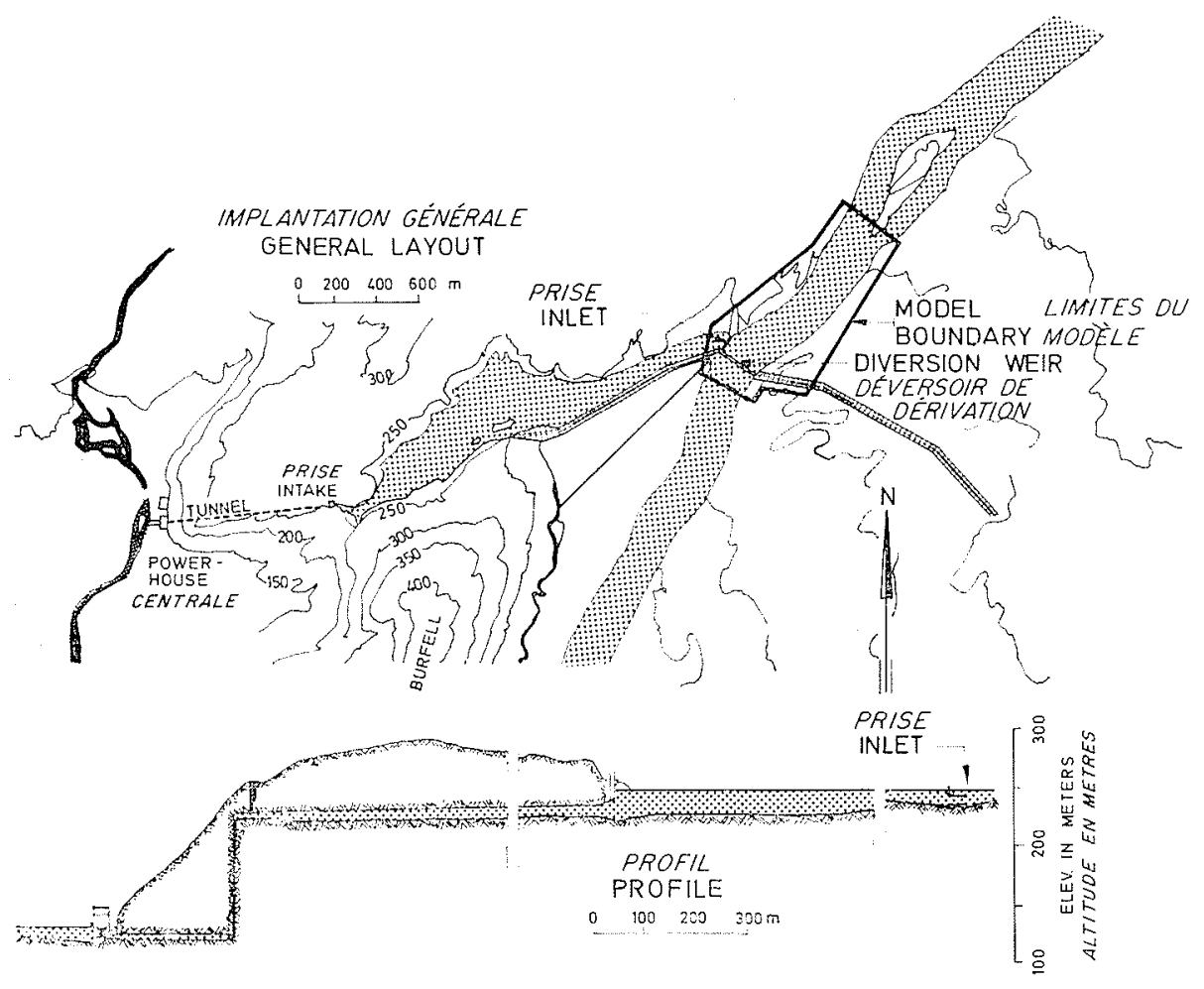

7/ Burfell project plan. Plan du projet d'aménagement de Burfell. 


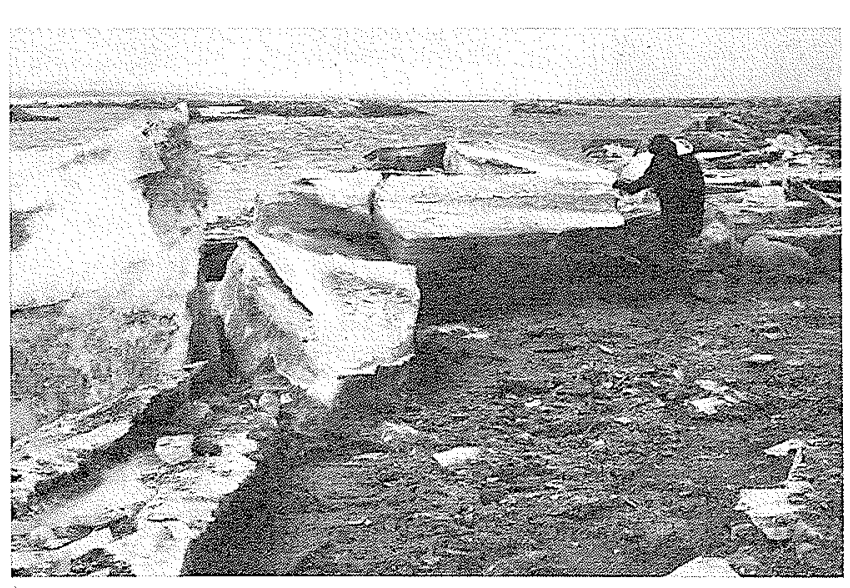

8/ Solid ice floes stranded at the Burfell dam site. Febr. 1, 1966.

Glacons massifs échoués à l'emplacement du barrage de Burfell. $1^{\text {er }}$ février 1966.

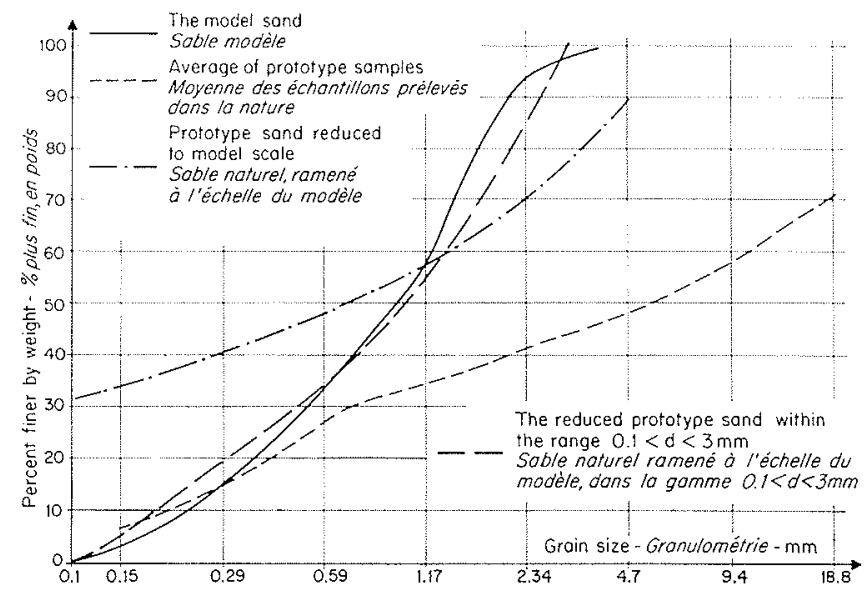

9/ Grain size curves for model and prototype. Courbcs granulométriques des matériaux sur le modele et dans la nature. itoring and facilities for passing ice floes. Figure 8 shows solid ice floes that have stranded near the Burfell dam site. The ice floes originated about $1 \mathrm{~km}$ upstream of the dam site.

Bed load. - Near the dam site the Thjorsá has a fixed bed of rough lava. Some $5 \mathrm{~km}$ upstream where the slope is less, there are sand and gravel deposits in the form of bars and along the banks. Grain size distribution curves for samples from these deposits are shown in Figure 9, indicating a mean diameter of $5 \mathrm{~mm}$. It is assumed that the river transports bed load past the dam site, but at a rate which is lower than its capacity for transport. The dam will reduce this capacity, and therefore the structure is equipped with a bed load excluder.

Suspended load. - The lack of vegetation facilitates land erosion by water and wind, so the river is normally turbid. In the back-water region created by the dam some of the suspended material must settle and join the bed load. The remaining "wash load" is carried by the flow and is therefore of no concern to the diversion structure.

\section{Phase relations.}

With a discharge of a wide size range of solids, both lighter and heavier than water, past the dam site, the diversion of water from the Thjorsá becomes a rather involved multiphase nroblem.

It is readily seen that the ice problem outstrips the sediment problem: The production of ice is governed by meteorological conditions which also cut down on the water discharge. Thus, exactly at the time water is most needed both for power and for passing ice, the discharge drops off. On the other hand, the sediment load is an increasing function of the water discharge, so one is always secured sufficient water to operate the bed load excluder.

A perfectly safe design would pass the probable maximum slush load, using less than the probable minimum of water discharge. However, the probability of these two events occurring simultaneously is extremely small. The low discharges of water are caused by storage in the back-water regions of ice dams and ice bridges. But these ice structures are at least to some extent built up of slush extracted from the river flow. Thus a severe reduction of the water discharge without a simultaneous reduction of the ice discharge is not easily conceivable.

A large supply of solid ice floes requires the breaking either of an ice dam or of bank ice, or both. The breaking of bank ice usually requires a flood flow. The breaking of an ice dam, whether it is caused by a flood or not, does create a flood. Thus it is difficult to conceive the river with a large load of solid ice floes unless the water discharge is substantial.

Based on the available observations and the reasoning outlined above the Thjorsá is assumed to obey the following rules:

1. Slush occurs in significant quantities only for below average water discharges;

2. The maximum slush discharge occurs for a range of water discharges, with a lower limit which is higher than the probable minimum flow;

3. Solid ice floes oceur in large quantities only during flood flows;

4. Sediments occur in significant quantilies only for above average water discharges.

The non-overlapping of the significant slush and sediment loads eased the model study considerably and permitted the linear, experimental approach illustrated in Figure 10.

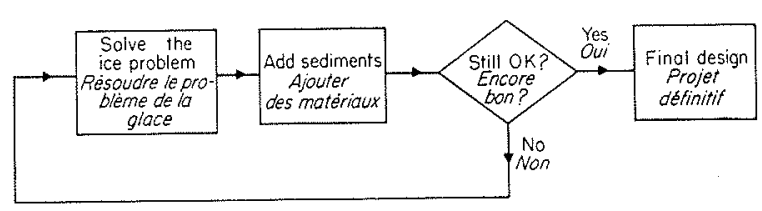

10/ Experimental method. La méthode expérimentale. 


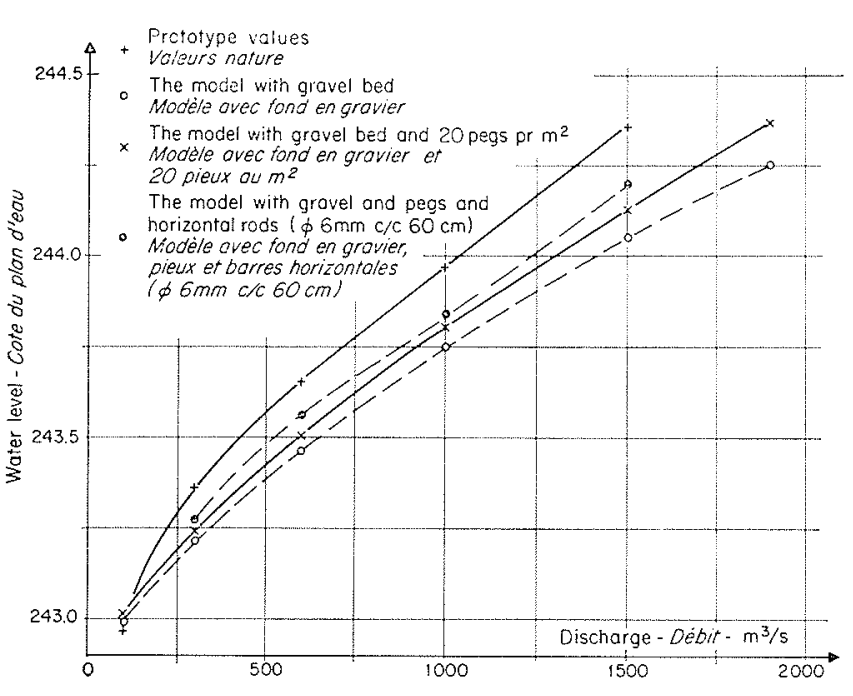

11/ Stage-discharge curves for model and prototype. Courbes hauteur-débit du modèle et de la nature.

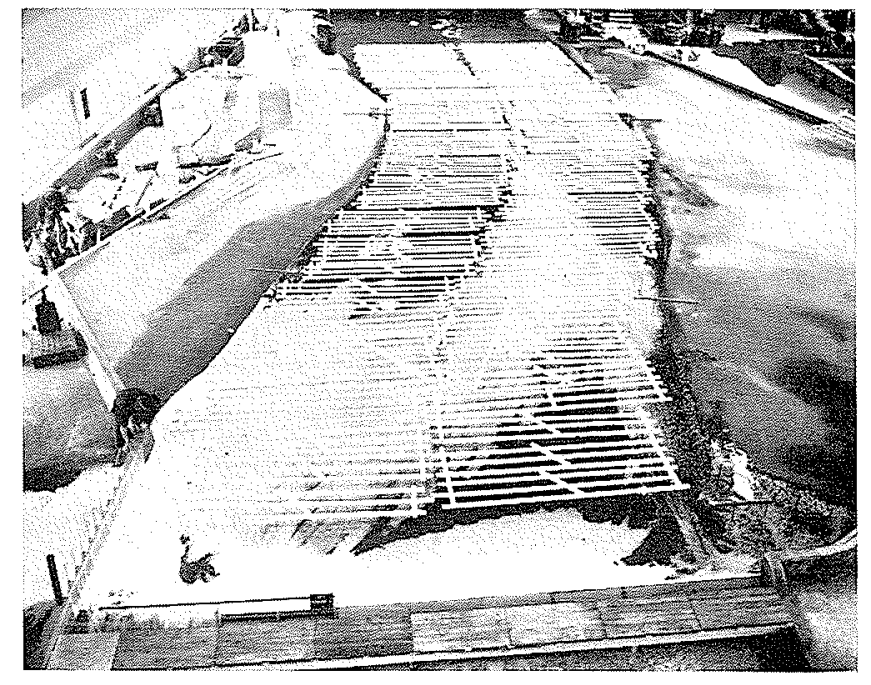

12/ View of the model / Vue d'ensemble du modile.

\section{The slush problem.}

The model investigation of the Burfell diversion concentrated on the slush problem for two reasons: First, large quantities of passive slush occur far more frequently than large quantities of other types of ice. Second, the mechanics of a twophase flow of water and small, slightly buoyant solids is not well known. To our knowledge, no model experiments with such flows have ever been performed.

Model slush. - The most important properties of passive slush are, for the individual ice particles, their specific gravity, size and shape, and for a floating layer, its porosity and shear strength. With the exception of the specific gravity of ice crystals hardly any information exists on the mechanical properties of slush. Sigurdsson (1964) estimated the porosity of slush samples at the dam site to 0.60 .

We made no attempt to unravel all relevant slush properties, but based our choice of model material on the following three criteria:

1. The model slush should respond to the turbulence level in the model, surfacing in regions of low turbulence and becoming suspended where the turbulence was high;

2. A floating layer of slush should be arrested by bank friction at low flow velocities and form bridges across the river;

3. The model slush should be durable and inexpensive.

Polyethylene shavings, of specific gravity 0.92 , grain sizes $2-6 \mathrm{~mm}$ and porosity 0.65 performed very well in preliminary flume tests and were used throughout the study to simulate passive slush in the model.

Polyethylene of the desired grain size was available with different grain shapes: regular cubes and cylinders, and irregular shavings. We chose the shavings, because their geometry would give the largest angle of internal friction.

The boundary friction was not manipulated in any way. Some adhesion was apparent between the model ice wall and the model slush, both of which were made of the same material.

\section{Model scales.}

'The vertical scale was limited to $\mathrm{H}_{r}=1: 20$ by the extremely small water depths in the prototype-only about $50 \mathrm{~cm}-$-for the crucial situations with a large slush load carried by a low flow.

The length of modelled river required for proper inflow was $1500 \mathrm{~m}$. This length plus $500 \mathrm{~m}$-the river width is about $300 \mathrm{~m}$-downstream of the dam reproduced to a horizontal scale $\mathrm{L}_{r}=1: 50$ exhausted the available space and the pumping capacity in the Laboratory.

With these geometric scales the lava bed was conveniently simulated by a natural $9-12 \mathrm{~mm}$ gravel and the bed load by a natural sand shown in Figure 9.

The slope distortion called for a distorted river bed roughness. The roughness elements had to be chosen such that the proper energy slopes were achieved without significant distortions of the flow pattern or of the transport of solids.

In a straight, wide and shallow river reach as the one modelled, the flow pattern is essentially preserved with almost any type of roughness that is randomly distributed on the river bed. Once the flow pattern is reproduced to satisfaction, the bed load movement is taken care of by a suitable choice of material.

It is common experience that distortion of already appreciable slopes calls for more friction than can be generated at the bed proper. Consequently one is forced to distribute friction throughout most of the depth of flow by means of drag elements such as pegs, strips of metal, or bits of mortar.

On the Burfell model the type of friction elements was determined by the effect on the surface transport of slush. Any conceivable, practical type of friction would penetrate the slush layer. Presumably, the drag elements would not only dissipate fluid energy, which they should, but also 
transfer shear forces from the solid phase of the slush layer to the bed, which they should not.

The transfer of shear forces from the slush to the friction element is partly through pressure forces on areas normal to the flow, and partly through friction forces on areas parallel to the flow. As the pressure can become much higher than the shear stress, the undesirable momentum transfer from the solid phase of the surface load to the friction elements depends primarily on the lateral dimension of these elements. But this is also true of the momentum transfer from the fluid.

In the present case a good solution to this dilemma was not found. The model was equipped with twenty $6 \mathrm{~mm}$ square pegs per $\mathrm{m}^{2}$, cut from a nail thread quality and fastened to wooden boards above the water surface. These pegs turned out to have drag coefficients not better than about 0.5 , due to rounded corners, instead of 2.0 as anticipated. The pegs therefore did not eliminate more than a fraction of the friction defect, as seen in Figure 11.

The effect of the pegs on the slush transport is to promote bridging, as explained above. A slight water depth defect and a correspondingly higher flow velocity might compensate for this, justifying to some extent the less than perfect model reproduction of the stage-discharge curve.

Figure 12 shows a picture of the model, with pegs in its middle reach.

\section{Model results.}

The relative merits of a sreat many modifications of the original design were tested on the model in the following way:

A certain volume of slush was dumped into the model at a constant rate $Q_{s}$, while maintaining a steady inflow of water $Q$ and diverting a steady discharge $O$ for power. For each design the maximum ratio $Q_{p} / Q$ that would not iam the inlet, could be determined as a function of $Q$ and $O$..

The model discriminated between good and bad design features down to surprisingly small details. A description of the more important design elements is given below.

The ietty. - The jetty was installed because the stagnation zone for the surface velocity component normal to the inlet produced a hump in the water level alon: the ice wall. The model ice could not be pulled over this hump towards the gates without reducing the discharge ratio $Q, / O$ bevond an acceptahle minimum.

Figure 12 shows an ice run for one of the designs without ieftr. Figure 13 shows a close-nn of the original inlet completely clogred.

For a given location of the ports the surface flow can be given the most favourable direction by means of a ietty with the proper length and lavout. A too short ietty would not turn the surface flow sufficiently parallel to the ice wall to prevent a stagnation zone above the upstream ports. A too long iefty would extend the backeddy so that the row of vortices orisinating at the tip of the ietty wonld hit the downstream ports and draw ice.

Figure 14 shows an ice run for one of the designs with a jetty.

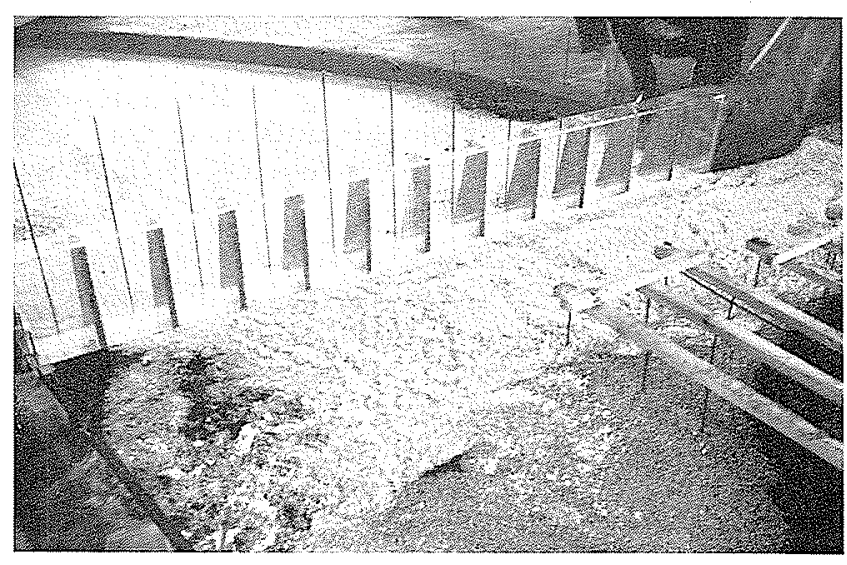

13/ Close-up of ice jam in the model. L'embácle sur le modèle.

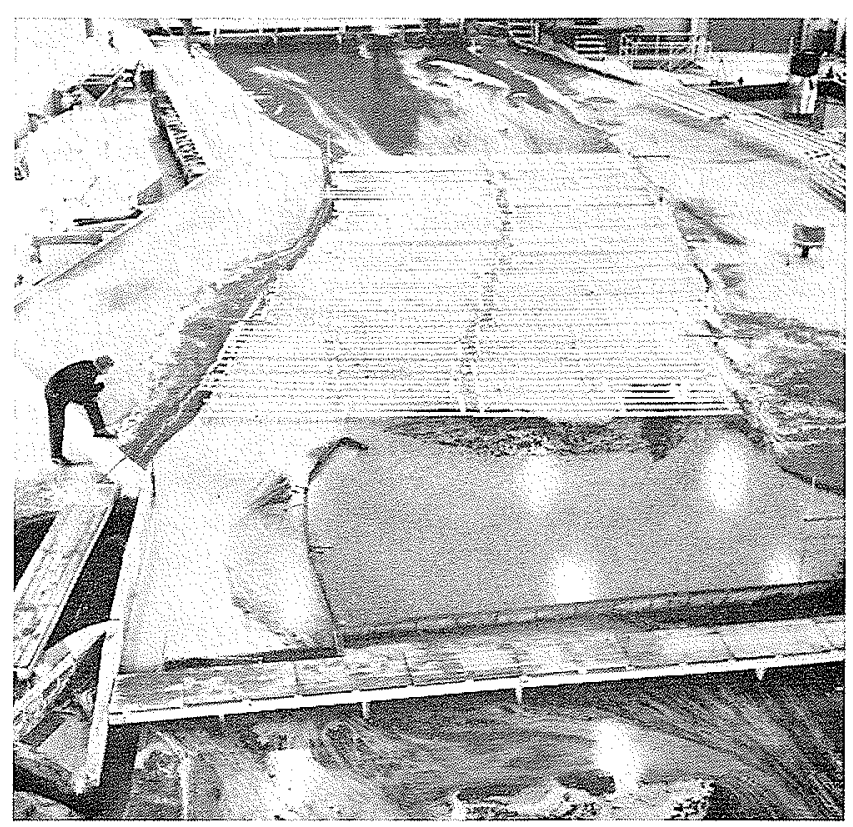

14/ Tee run in the model with jetty.

Charriage de glaçons sur le modile comportant une jetée.

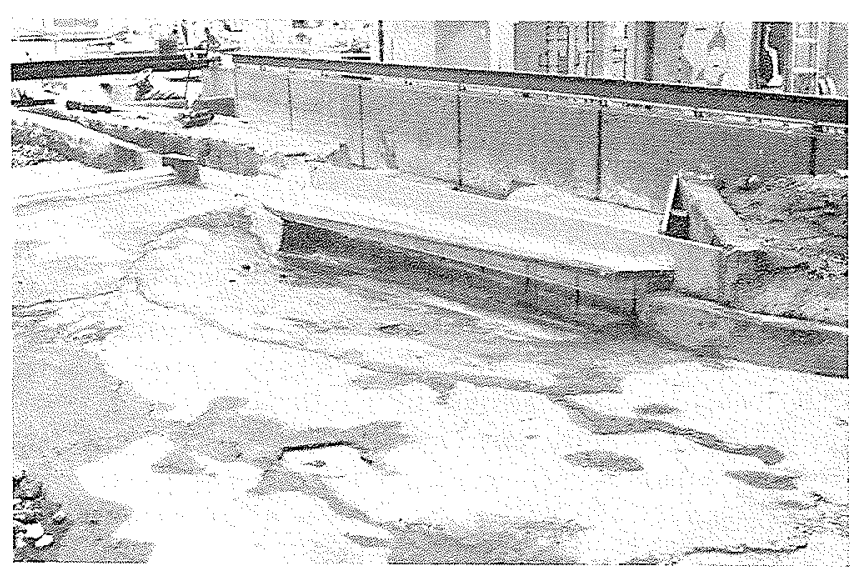

15/ Excavation near the inlet

Creusement du lit au poisinage de la prise. 
After the tests were completed, we learned that a very similar jetty had been worked out by Ontario Hydro's hydraulic laboratory for the Sir Adam Beck intakes on the Niagara River, already some 15 years ago. For the author it was very reassuring to watch the performance of the completed structure.

The excovation. -- The excavation in front of the inlet is intended as a settling basin in which the slush is given a chance to surface and the sediments a chance to settle.

In order to pass through the inlet ports, the flowing water has to change its direction from nearly horizontal to some angle with the horizontal. The vertical velocity component imposed on the flow transports ice into the diversion canal.

The model showed that if the trench in front of the inlet was widened and given a milder slope, the ice intrusion would decrease. An excavation which gave neither excessive vertical velocities nor excessive turbulence and therefore allowed the already suspended model ice a chance to surface in front of the ice wall, is shown in Figures 15 and 18 . The total excavation is much greater than for the original design, and the port area has been increased from 240 to $300 \mathrm{~m}^{2}$.

The excavation should not be deep near the weir, because the weir discharge would tend to be drawn from the lower, ice-free layers of flow. The upper, ice-rich layers were held back by wall friction, which was transmitted throughout the floating slush layer by internal shear. Figure 13 from the original design shows an ice bridge in front of the Bjarnalakur weir, which wastes clear water instead of passing ice. For this reason the inlet ports were moved upstream, so as to give a gently sloping approach to the weir.

As shown in Figure 16, the sand settled on the wrong side of the original inlet structure. While this would not be detrimental to the operation of the power plant, it would require occasional dredging. A sand excluder was therefore incorporated in the design.

The sand excluder is shown in Figure 17. It is an adaptation of a previous design by the consultant, and it worked very well in the model.

The skimming trough. - With the excavation revised and the jetty added the model satisfied the set of design tests. However, the floating layer moved only very slowly during the most severe. tests. A little more wall friction or internal shear strength presumably might arrest the floating layer and jam the inlet. This uncomfortable thought made us look for solutions involving less frictional resistance for the floating layer, since its shear strength would be beyond our control. A side channel spillway suspended on the ice wall proved to be the answer to the friction crisis. This skimming trough, shown in Figure 18, has a horizontal weir about the length of the inlet. The floating slush layer is drawn over the weir and into the trough with a minimum of resistance. Once trapped in the trough, the slush is kept moving by a suitable channel slope and passed over the dam.

The final design of the skimming trough was based on extreme ice conditions and worked out on a 1:40, undistorted model. As shown in Figure 15 the side weir was stepped to give a more uniform inflow. A skirt was extended in front of the inlet ports in order to ease the separation of the surface flow from the power water.

The skimming trough does not benefit from the jetty and would probably work better without it. Nevertheless, the jetty has been kept because it improves very much the ice-passing capacity of the gated dam section. If the slimming trough should be blocked, by mechanical failures, freezing or otherwise, the dam gates must be used. On the model the gates alone also satisfied the design tests.

One can argue, on very plausible terms, that the skimming trough will promole formation of anchor ice. The reason is that the turbulence intensity is higher within the trough than outside, so a supercooling that is feasible in the approaching flows, cannot survive in the trough (Carstens, 1966). Therefore, if the river is supercooled, anchor ice is likely to accumulate in the skimming trough as the flow adjusts its temperature to the prevailing turbulence level.

However, this argument does not really interfere with the usefulness of the skimming trough. Even if it gets clogged by active ice, the situation does not get any worse than it would without the trough. As long as the trough remains open, it saves water, and if the trough is filled with ice, it does not interfere with the passing of ice over the gates.

Figure 19 shows a cross-section through the final inlet structure, with the skimming trough on top.

The side channel. - Once the ice has been passed over the dam, it may continue either down the river or through the Bjarnalækur Canal to a creek which joins the river below the water fall Trollkontuhlaup. It seemed desirable to have a choice between these two possibilities regardless of where the ice passes the dam. For this purpose the side channel was conceived, a sort of side channel spillway connecting the river with the Bjarnalekur Canal immediately downstream of the dam [in Figure 20 and foreground in Figure 18].

The side channel is normally closed by the gate seen in Figure 18.

\section{Sediment deposits.}

In the back-water regions of the dam sediments are likely to deposit. Various configurations of such deposits were tested for possible, adverse effects on the flow of ice.

The skimming process turned out to be little, if at all, influenced by the river topography upstream of the jetty. However, if a sediment front advanced into the excavated area as shown in Figure 21, the "settling" of slush was hampered by the increased turbulence created through flow separation from the bed. Such deltas were ohserved whenever large sediment loads were fed into the model. The sediments then adjusted the bed slope to the back-water surface slope, covering the bed with a layer that increased in thickness towards the dam. 


\section{Interpretation of model results.}

Comparison of model slush with natural slush.-Lacking prototype data for a rigorous verificaition of the model, we had no way of extracting quantitative information from the experiments. The model was built to yield qualitalive information on the slush-passing capacity of the diversion dam by observing the performance of a model slush.

As model slush was chosen a material which possesses those properties that we considered relevant: For the individual particles, a buoyancy matching the turbulent forces in the model, for a floating layer, a shear strength sufficient to cause bridging at low flows. The model results will be essentially correct for slush with properties within a cerlain range. The validity of the model results thus depends on whether or not we have succeeded in finding reasonably accurate values of the Rouse number $w / x u *$ and the "shear numbers" $\tau_{i} / \rho u^{2}$ and $\tau_{b} / \rho u^{2}{ }^{2}$, where $\tau_{i}$ is the internal shear strength of a floating slush layer and $\tau_{b}$ is the shear strength that can be generated between this layer and the solid boundaries.

What we consider a reasonably correct Rouse number was obtained by comparing the model slush with the kind of natural slush seen in Figures 4 and 5. Among the suitable model materials with Rouse number of the right order of magnitude, we picked the material having the largest angle of internal friction.

An equally good estimate of the shear strength would call for observations of the initial formation by passive slush of bridges, which we did not have at the time. Evaluation of the shear strength of old ice bridges will give too conservative answers, because the shear strength increases with time primarily for two reasons:

a) Freezing, in contrast to the merely mechanical interlocking of passive particles, provides a number of active bonds, both within the slush matrix and between the floating layer and its boundaries;

b) Dynamic compression, in the sense of Devik (1965), rapidly strengthens an ice bridge. The pounding of such a bridge, by turbulent eddies and surface waves, increases the internal shear strength, just as the compaction of snow, sand and indeed any porous medium. The relative motion caused by shear failures (shoves) has a similar effect.

A good illustration of these effects is provided by the canyons through old ice jams, as shown in Figure 22. The former, loose slush has been compacted to densities as high as 0.8 and has sufficient shear strength to hold vertical walls $5-10 \mathrm{~m}$ high, or the same as good clays (Devik, 1966).

As the model slush is neither freezing nor compacted, the model results become unrealistic as soon as an ice bridge has formed. On the other hand, up to this point almost any model shear is probably too much for a passive slush. The scale ratio for shear slrength $\tau_{,}$, is less than the vertical scale ratio $H$. for a distorted model in our case $\tau_{\text {. }}<1 / 20$. Therefore, as long as there is little freezing so the slush is essentially passive, and not much compaction, the model results should be acceptable.
One experimental observation that greatly eases the discussion on the correct modelling of slush is the insensitivity of the final design to changes within its general layout. There is nothing very critical about most of these designs, in fact there was a surprising latitude of acceptable solutions with different jetties, different number, size and submergence of ports, and different excavations. For this reason we feel that the model results apply to a rather wide range of passive natural slush.

Significance of the test programme.-While the slush load can be predicted from ice surveys and weather forecasts and the sediment load from the river flow and weather forecasts, one cannot as yet predict the bursting of an anchor ice dam. The flash floods caused by such bursts, with their load of solid ice floes, will remain a constant threat to the diversion as long as there are significant volumes of underwater ice in the river.

When the dam is hit by a flood wave carrying a large amount of solid ice floes, the gates must be lowered. However, once the gates are properly set, they have a large capacity for passing ice floes when there is sufficient streamflow. The flash floods, sometimes probably arriving at the dam on very short notice, therefore are a monitoring headache rather than a serious design problem.

Because high slush loads are correlated, generally speaking, with low flows, there is always a good chance that some of the water spent on passing slush, cuts down on valuable, prime power. The capacity of the diversion dam for passing slush therefore is a design problem of first importance.

The flexibility of the final design leaves the dam operator with a number of possible actions. A guideline giving the sequence of operations which minimizes water losses is shown schematically in Figure 23. Most of the critical situations foreseen in the flow sheet of operations never occurred on the model. Some of the paths are required by hypothetical ice jams downstream of the model reach. Other paths become necessary when freezing and/or compaction invalidate the model results obtained for a passive slush.

\section{Concluding remarks}

From a fluctuating, multiphase flow in the Thjorsa, the Burfell diversion is designed to withdraw, at a fairly constant rate, the fluid phase only. The Thjorsá carries two solid phases, but usually not simultaneously. The light solid phase consists of various categories of ice, among which an easily suspended, passive slush predominates. The heavy solid phase consists primarily of a coarse, volcanic sand.

The first step in the diversion is to provide for an orderly settling of the solids that are suspended. To this end a low dam is planned across the river, creating a back-water reach. Upon entering this reach the light solids gravitate towards the free surface and the heavy solids towards the bed.

The nexl step is the actual diversion of the intermediate layers of flow, while encouraging the sur- 
23/ Flow sheet for ice-passing operation. Schéma des consignes d'évacuation des glaces.

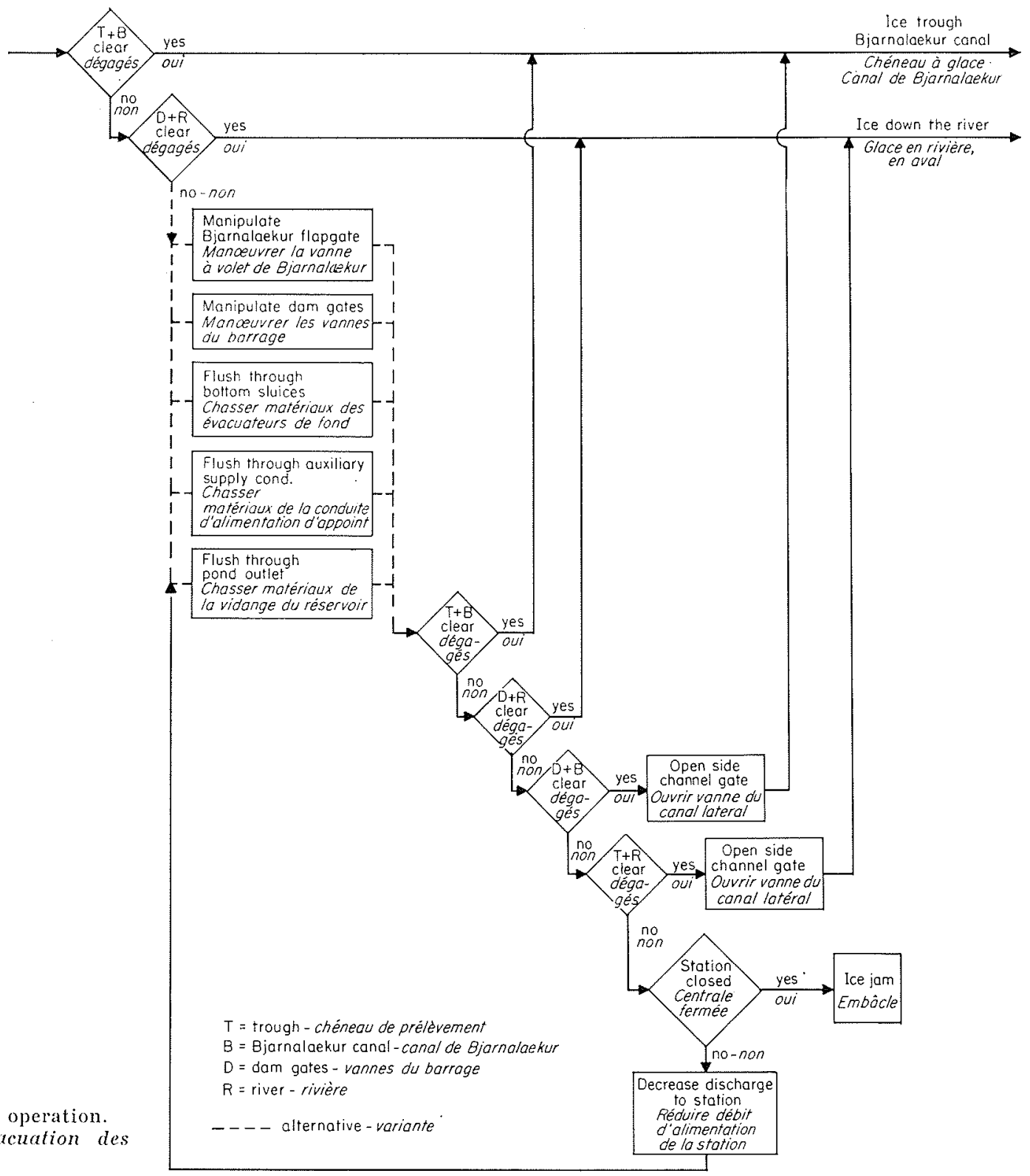

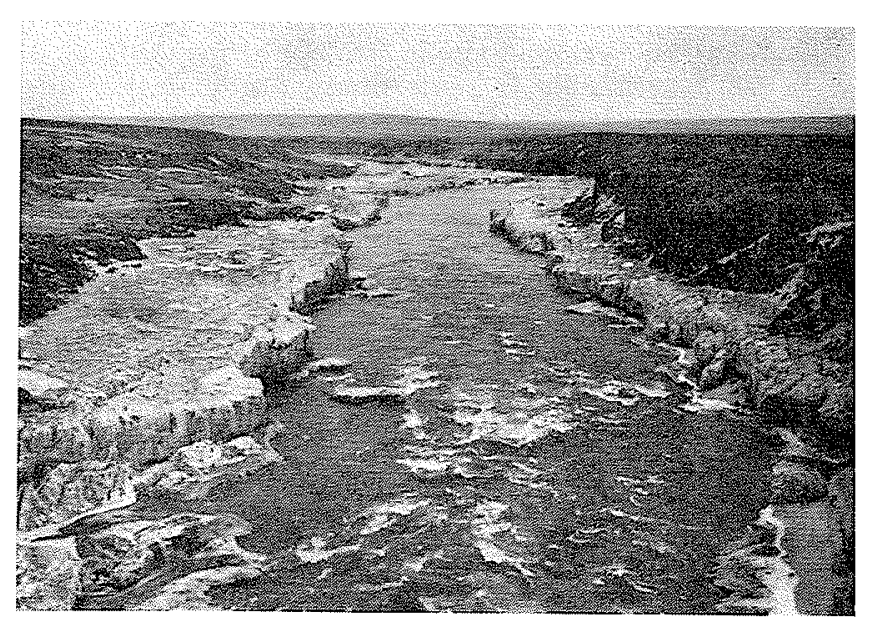

22/ Canyon through slush accumulation, Thjorsá.

La Thjorsá s'est frayé un «canyon» par ses glaces fondantes accumulées. face and bottom layers to continue down the river. For this purpose the inlet structure shown on Figs. 15,18 and 19 has been developed.

The change of direction for the intermediate layers introduces additional shear in the flow, and so the second step above interferes with the first step. Model tests showed that this problem could be best solved by delaying any relative directional changes between the flow layers until the layers were safely trapped in their respective stories in the three-storey intake of Fig. 19, and can no longer mix.

The ground floor is a conventional bed load excluder, and the first floor is an ordinary submerged inlet. The second floor, essentially a side channel spillway, combines a smooth approach flow, and therefore a highly effective skimming, with a large transport capacity. Skimming structures of this kind are pictured in Zamarin's (1965) textbook and appear to be common in the U.S.S.R. 


\title{
T. CARSTENS
}

The various components both of the hydraulic problem at the Burfell diversion and the physical structures chosen to accomplish the diversion, are encountered elsewhere. What makes the Burfell diversion unique, is its superposition of flow problems and the consequent need for many hydraulic structures synthesized into one.

\section{References}

Canstexs (T.). - Experiments with supercooling and ice formation in flowing water. Geof. Publ. XXVI, (1966) 9

Devik (O.). … Production of pack ice and ice bridges from floating sludge ice in rivers. IAIR XI Congr. V, (1965) 1.4 .
DeviK (O.) and Kanavix (E.). - Kvitá and Thjorsá River systems, Iceland. Analysis and considerations of the ice conditions. Unpubl. rep. UN Spec. Fund. (1965).

Havssen (R.) and Galana (G.). - Transportation and deposit of frazil ice under ice covers. IAHR VII Congr. 6-SI-1.

Mremes (B.). - Theory of formation and deposit of frazil ice. Eastern Snow Conf. (1963), 8, 129.

PARISET (E.) and HAusser (R.). - Formation of ice covers on rivers. IAHR VII Congr. (1959), 3-SI-1.

Srgcndsson (G.). - Ice observations at Burfell FebruaryApril 1963. Reykjavik, Raforkumalastjori (1964).

Tesarer (E.). - Bull. $8 \mathrm{~F}$, River and Harbour Researeh Labowatory. Techn. Unib. of Norway (1966).

VANoxi (V.A.). - Transportation of suspended sediments by watel. Trans. ASCE, (1946), III, 67.

Zamarin (E. A.) and Fanderv (V.V.). - Hydrotechnical Structures (in Russian), Moscow, Kolos, 5th ed. (1965).

\section{Résumé}

\section{L'hydraulique du transport des glaces en rivière}

\author{
par T. Carstens *
}

La première partie du rapport décrit l'éconlement général à deux phases de grains de matériaux solides flottants, transportés par un écoulement à surface libre.

Nous examinons le mode de transport, par un courant d'eau de densité $\rho$ de matériaux solides légers de densité $\rho_{s}<\rho$, et nous le confrontons avec le transport, mieux connu, de matériaux solides de densité $\rho s>\rho$. Nous avons pu déterminer une analogie complète pour la répartition des grains en suspension en fonction de la concentration, essentiellement parce que, du fait de la composante de turbulence verticale, l'écoulement constitutif correspondant présente la même condition aux limites tant au fond qu'à la surface libre. Il n'y a aucun «charriage de surface» analogue au charriage de fond, parce que le fond est au repos, alors que la surface libre est animée d'une vitesse moyenne.

La deuxième partie du rapport examine la validité du modèle théorique pour la représentation des matériaux solides flottants dans les rivières, et en particulier pour l'étude du charriage de glace du genre de celuj représenté sur les figures 4 et 5 .

La troisième partie du rapport traite de l'étude sur modèle du barrage de dérivation de Burfell sur la rivière Thjorsá en Islande, dont l'abondance des glaces lui confère une certaine renommée (fig. 22). Le modèle fut réalisé au Laboratoire d'Etudes Fluviales et Portuaires de l'Université Technique de Norvège à Trondheim; il est représenté sur la figure 12. La glace fondante naturelle passive y a été représentée avec réalisme à l'aide de copeaux de polyéthylène, et le modèle a fourni de nombreuses indications fort utiles pour le calcul des ouvrages exposés au passage de cette glace du type le plus courant par le barrage.

Cependant, alors que la glace flottante représente la phase solide la plus importante de l'écoulement, par contre, elle n'est pas la seule phase solide : en effet, la rivière transporte également un certain volume de limon, de sable et de gravier d'origine volcanique. La dérivation de Burfell a pour objet la soustraction de la seule phase fluide de l'écoulement à phases multiples dans la Thjorsá.

On laisse d’abord les phases légères se concentrer à la surface libre, et les phases relativement lourdes an fond, dans un bassin de décantation créé d'une part par un barrage de faible hauteur à travers la rivière, et d'autre part par un approfondissement localisé du lit de la rivière (fig. 19).

Ensuite, on dérive les couches intermédiaires de l'écoulement, et on fait passer les couches superficielles, et du fond, par le barrage. Les couches du fond sont retenues au « rez de chaussée 》 de la prise à trois étages dont la section transversale est représentée sur la figure 20 et les photos des figures 15 et 18 . Le débit de la centrale est dérivé au «prenier étage» de l'ouvrage, et les couches superficielles sont retenues à l'étage supérieur.

L'ensemble de cet ouvrage de prise correspond a une combinaison de trois ouvrages hydrauliques classiques, ni plus ni moins : le «rez de chaussée " est un piège à matériaux, le «premier étage» est une prise noyée, et l'étage supérieur est un déversoir latéral (chéneau de prélèvement).

Un autre élément peu habituel de l'ensemble (bien que non sans précédent) est représenté par la jetée, enracinée au barrage et dont l'alignement est parallèle à la prise (fig. 14). Elle a pour objet de réduire les charges dynamiques créées par la composante d'écoulement normale a la prise, lorsque le chéneau de prélèvement est hors de fonctionnement. La présence de telles pressions à la prise gênerait le passage de la glace par les évacuateurs du barrage mobile.

L'ouvrage de dérivation de Burfell est actuellement en cours de réalisation par des entreprises islandaises, danoises, et suédoises, travaillant en collaboration. L’ingénieur-conseil est la Harza Engineering International (Chicago), et le maitre d'œuvre est le Landsvirkjunn (Islande). 